\title{
FOREST AND FOREST CHANGE MAPPING WITH C- AND L-BAND SAR IN LIWALE, TANZANIA
}

\author{
J. Haarpaintner ${ }^{\text {a }}$, C. Davids ${ }^{\text {a }}$, H. Hindberg ${ }^{\text {a }}$, E. Zahabu ${ }^{\text {b }}$, R.E. Malimbwi ${ }^{\text {b }}$ \\ ${ }^{a}$ Norut, P.O. Box 6434, Tromsø Science Park, N-9294 Tromsø, Norway - joergh@ norut.no \\ ${ }^{\mathrm{b}}$ Sokoine University of Agriculture, Morogoro, United Republic of Tanzania
}

THEME: BIOD - Forests, Biodiversity and Terrestrial Ecosystems.

KEY WORDS: REDD+, Forest, Forest Change, SAR, Tanzania

\begin{abstract}
:
As part of a Tanzanian-Norwegian cooperation project on Monitoring Reporting and Verification (MRV) for REDD+, 2007-2011 Cand L-band synthetic aperture radar (SAR) backscatter data from Envisat ASAR and ALOS Palsar, respectively, have been processed, analysed and used for forest and forest change mapping over a study side in Liwale District in Lindi Region, Tanzania. Land cover observations from forest inventory plots of the National Forestry Resources Monitoring and Assessment (NAFORMA) project have been used for training Gaussian Mixture Models and k-means classifier that have been combined in order to map the study region into forest, woodland and non-forest areas. Maximum forest and woodland extension masks have been extracted by classifying maximum backscatter mosaics in HH and HV polarizations from the 2007-2011 ALOS Palsar coverage and could be used to map efficiently inter-annual forest change by filtering out changes in non-forest areas. Envisat ASAR APS (alternate polarization mode) have also been analysed with the aim to improve the forest/woodland/non-forest classification based on ALOS Palsar. Clearly, the combination of C-band SAR and L-band SAR provides useful information in order to smooth the classification and especially increase the woodland class, but an overall improvement for the wall-to-wall land type classification has yet to be confirmed. The quality assessment and validation of the results is done with very high resolution optical data from WorldView, Ikonos and RapidEye, and NAFORMA field observations.
\end{abstract}

\section{INTRODUCTION}

As part of the Group on Earth Observations Forest Carbon Tracking Task (GEO FCT) and following Global Forest Observations Initiative (GFOI), a Norwegian-Tanzania cooperation project was established. The goal is to support Measuring, Reporting and Verification (MRV) for REDD+ initiative, which aims to be a financial incentive for tropical countries to reduce deforestation and forest degradation (REDD+).

An important research issue inside GFOI is to investigate the role of synthetic aperture radar (SAR) in establishing national forest monitoring systems and develop robust methods to map forests and forest change (GFOI, 2013; Haarpaintner et al., 2012). Two study regions are investigated in this NorwegianTanzanian project by airborne LiDAR as well as by satellite remote sensing: the Amani forest reserve and a large study region of the Liwale district in the Lindi region in Tanzania. Here we focus on the use of C- and L-band SAR of the Liwale study site. L-band SAR is generally better suited than C-band SAR for forest monitoring as its longer wavelength better penetrates the forest canopy. L-band SAR data is provided by the Japanese ALOS satellite with its Palsar sensor. C-band SAR data is provided by the European Space Agency's Envisat A(dvanced)SAR. The project should complement the National Forestry Resources Monitoring and Assessment (NAFORMA), which is a nation-wide forest inventory program that has collected a total of more than 36000 forest plots (Tomppo, 2014).

This paper presents forest mapping results from both ALOS Palsar and Envisat ASAR individually as well as combined, and yearly forest change detection from ALOS Palsar only.

\section{THE LIWALE STUDY SITE}

The Liwale study site of about $15000 \mathrm{~km}^{2}$ is located in the Lindi region in the south-east of Tanzania. There are large forested areas mainly in the north and west of the site, but the majority land type is scattered open to close Miombo woodland. The north-eastern quadrant of the study site has little vegetation, dominantly open (Miombo) woodland and non-forest areas.

Fig. 1 shows the location of the Liwale study site in Tanzania.
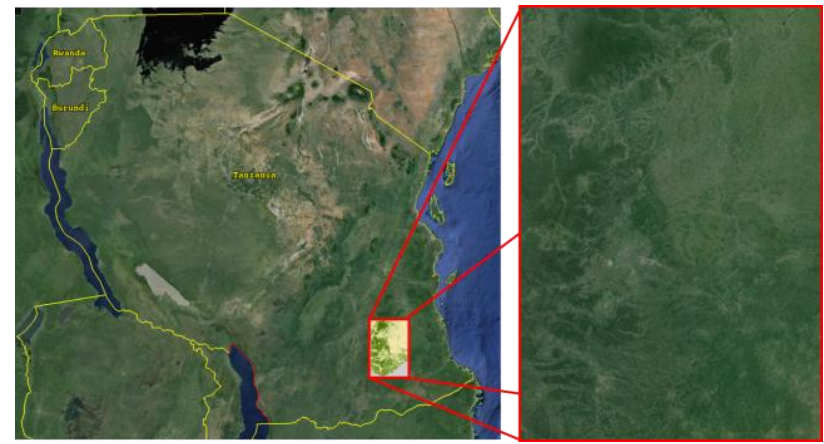

Figure 1. The location of the Liwale study site in Tanzania (C) GoogleEarth). 

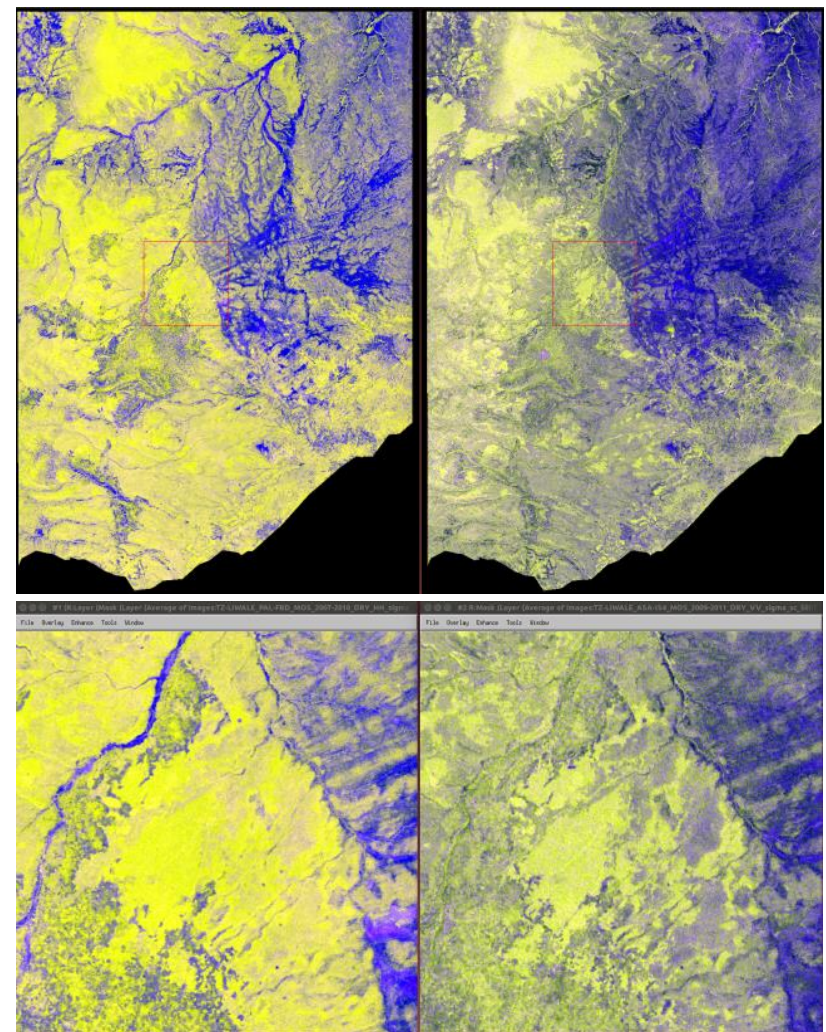

Figure 2. (Upper panels) 2007-2010 averaged ALOS Palsar image (left) and 2009-2011 averaged Envisat ASAR APS image (right) over the Liwale study site. (Lower panels) red rectangle zoom.

\section{SAR PRE-PROCESSING}

SAR pre-processing, i.e. georeferencing, radiometric calibration and slope correction, has been done with Norut's in-house developed GSAR software (Larsen et al., 2005) using the SRTM.v4 DEM. An advanced sigma nought $\left(\sigma^{\circ}\right)$ correction was introduced to the pre-processing in order to account for an angle dependency of the illuminated area, according to Shimada \& Takahiro (2010) and Ulander (1996). The 2007-2010 ALOS Palsar Fine-Beam Dual (FBD) data in HH and HV polarization has been then processed into yearly dry season mosaics. Furthermore an average as well as a maximum backscatter (per pixel) mosaic for the dry season have been established for the four year period in order to build a maximum forest extent mask to filter out changes in non-forest areas (see section 5) for the forest change product. The same has been done for the 20092011 Envisat ASAR alternate polarization (APS) data in VV and VH polarizations. As Envisat ASAR APS data however is far more noisy and variable because of higher sensitivity for humidity and phenology effects, the Envisat ASAR APS average backscatter in VV and $\mathrm{VH}$ have been used only for forest mapping. The average backscatter images for ALOS Palsar FBD data and for Envisat ASAR APS data for the periods 2007-2010 and 2009-2011, respectively, are shown in Fig 2. The RGB channels are (R) co-polarization (HH for Palsar and VV for ASAR), $(\mathrm{G})$ cross-polarization (HV for Palsar and $\mathrm{VH}$ for ASAR), and only for presentation purposes (B) the normalized difference index (NDI) describing the ration between the co-polarization XX (i.e. HH or VV) and crosspolarization $\mathrm{XY}$ (i.e. $\mathrm{HV}$ or $\mathrm{VH}$ ) backscatter as:
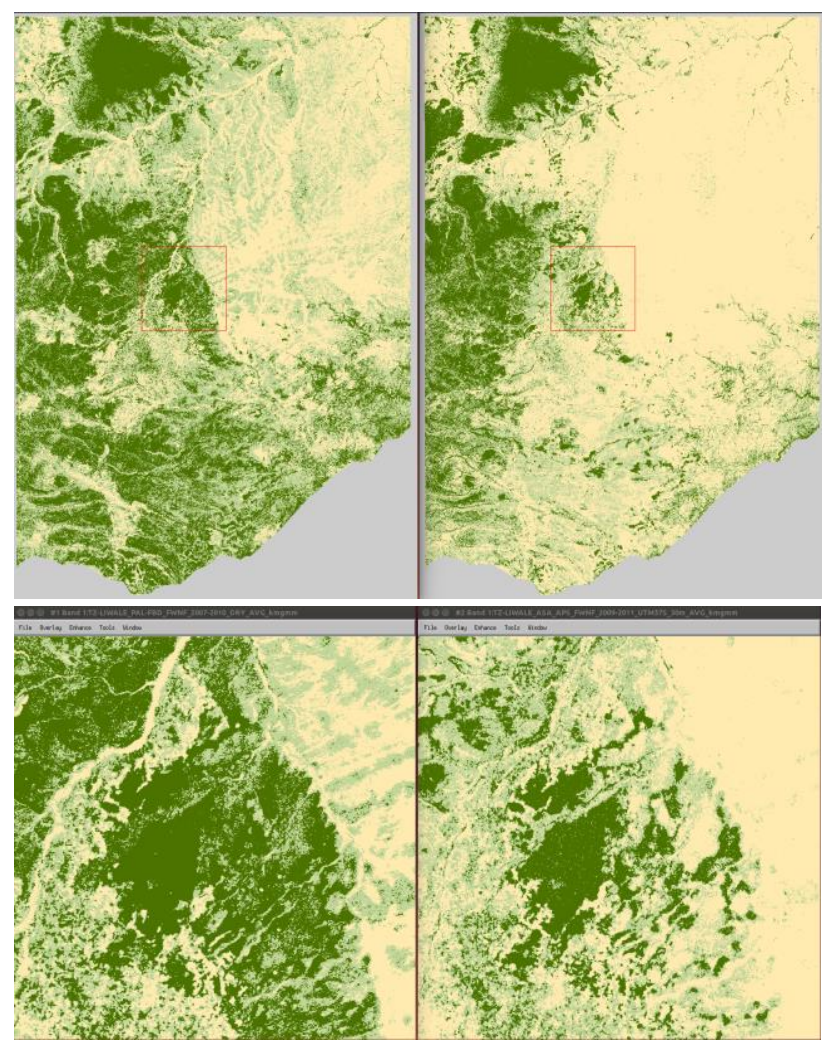

Figure 3. Forest/Woodland/Non-forest classification from averaged ALOS Palsar FBD (left) and Envisat ASAR APS (right). Lower panels show the red rectangle zoom. Forest in dark green, woodland in light green, and non-forest in beige.

\section{FOREST/WOODLAND/NON-FOREST MAPPING (FWNF)}

Ground reference data has been collected as forest plots through the NAFORMA project providing vegetation types at each plot location. As it is unrealistic that each NAFORMA land/vegetation type is detectable in SAR data, the different types have been aggregated into three main classes: forest, dense woodland and non-forest; resulting in a higher number of training sites for each class for the classification algorithm. In order to reduce speckle of the SAR data, the data has been temporally averaged over the totality of available data, which are the dry seasons of the years 2007-2010 and 2009-2011 for ALOS Palsar FBD and Envisat ASAR APS data, respectively.

\subsection{Single sensor approach}

Each of these averaged data sets have then been classified using the co- and cross-polarization band (HH/HV for ALOS Palsar and $\mathrm{VV} / \mathrm{VH}$ for Envisat ASAR) and with these training sites into forest, woodland and non-forest areas using two methods that are part of Norut's GSAR software package: the Gaussian Mixture Model (GMM) and the k-means (KM) classifier. The two classification results, GMM and $\mathrm{KM}$, have then been combined into one classification taking, by priority, the maximum extent of forest, the maximum extent of woodland and the rest as non-forest areas. Fig. 3 shows these classification results using the ALOS Palsar mean backscatter $\mathrm{HH}$ and $\mathrm{HV}$, and the Envisat ASAR APS mean backscatter in VV and VH. Obviously, using this method, ALOS Palsar FBD detects more forest and woodland than Envisat ASAR APS. 

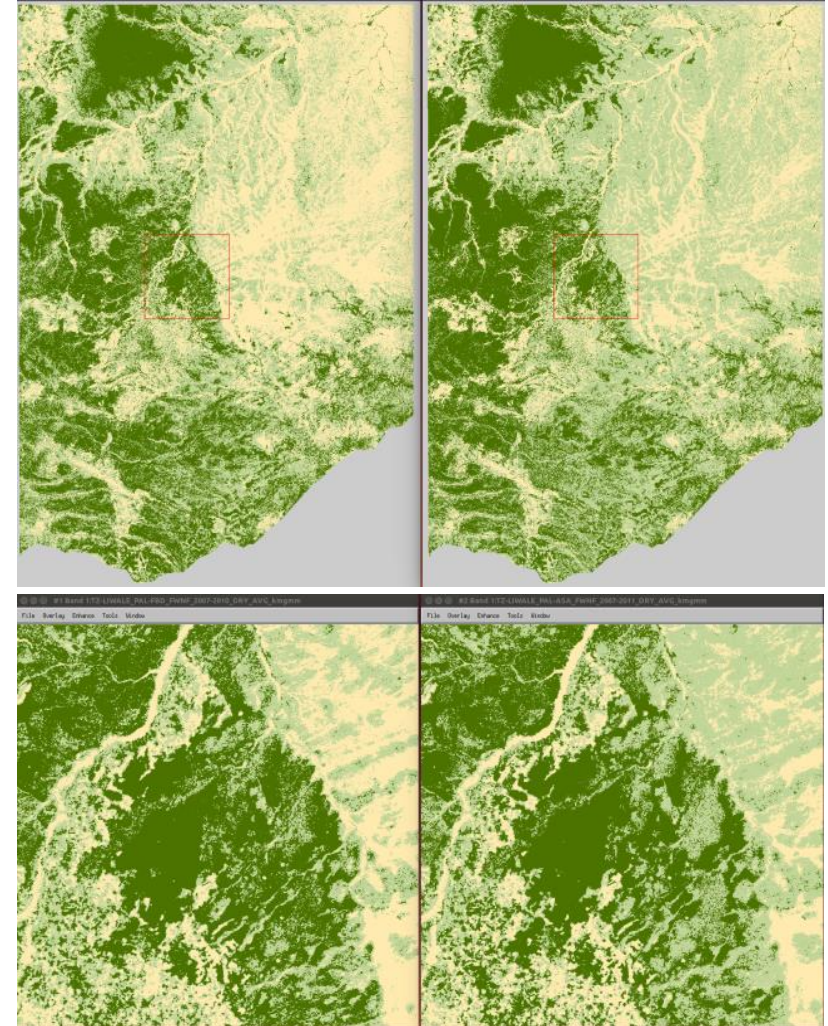

Figure 4. Single sensor classification with ALOS Palsar (left) versus multi-sensor classification using ALOS Palsar and

Envisat ASAR (right). Lower panels are enlargements of the red rectangles. Forest in dark green, woodland in light green, and non-forest in beige.
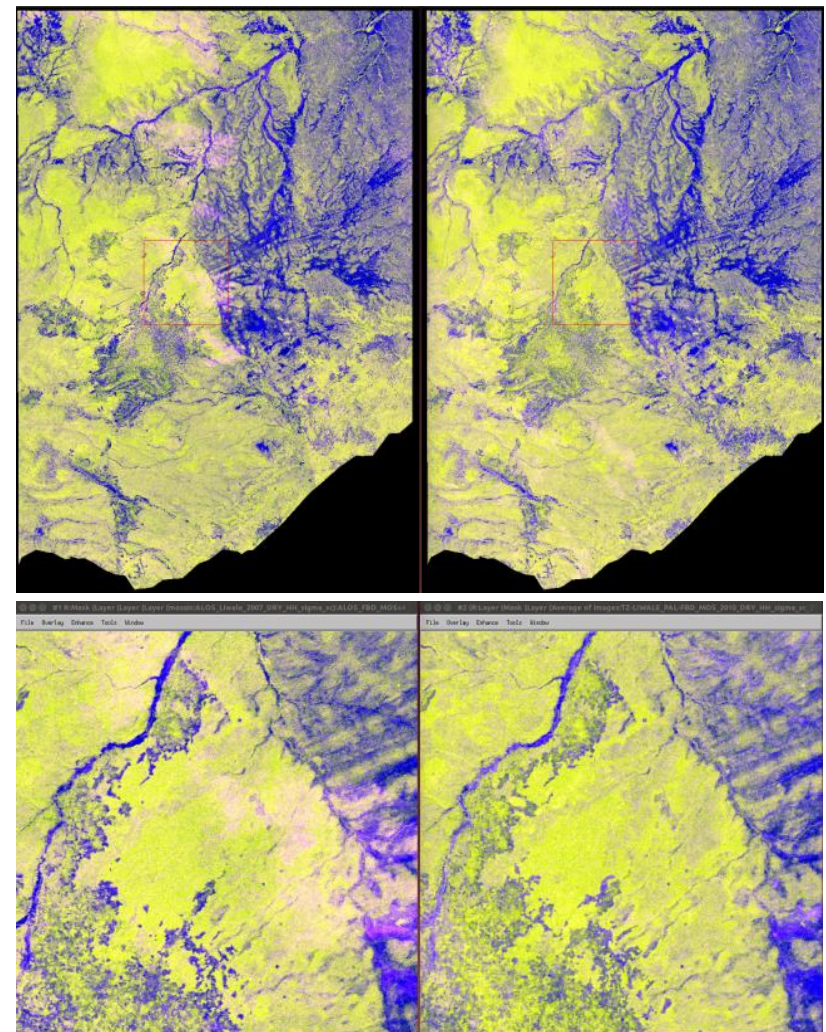

Figure 5. 2007 (left) and 2010 (right) ALOS Palsar mosaic. Rectangle enlargements in lower panel.

\subsection{Multi-sensor approach (C- and L-band SAR combined)}

Using the same classification approach than in 4.1., i.e. combing the GMM and KM classification, in the multi-sensor approach, we feed the classifier with all averaged backscatter channels, i.e. Palsar (HH), Palsar (HV), ASAR (VV) and ASAR $(\mathrm{VH})$. The multi-sensor results from the C-and L-band SAR combination is shown in Fig. 4 in comparison with the individual ALOS Palsar classification result. The forest area extent is very similar in both classification, but the multi-sensor approach classifies a larger area into woodland especially in the north-eastern area, even though Envisat ASAR individually classifies this area in large majority into non-forest.

\section{INTER-ANNUAL FOREST CHANGE FROM ALOS PALSAR HV}

Inter-annual forest change has been detected by subtracting the ALOS Palsar HV backscatter image of year $(y+1)$ from year $y$. All pixels with a decrease stronger than $3 \mathrm{~dB}$ are considered as forest or woodland loss and all pixels with a variation of $+3 \mathrm{~dB}$ are considered as forest gain. Prior to this step the maximum ALOS Palsar HH and HV backscatter mosaics have been classified into forest, woodland and non-forest and the result is used to mask out changes in non-forest areas, which are mainly due to difference in ground humidity variation, precipitation or agriculture changes. Inter-annual changes have been detected for the consecutive years 2007-2008, 2008-2009, 2009-2010 as well as for the three year period 2007-2010. The strong agreement between the sum of the forest loss of the consecutive years and the directly detected three year loss from 2007 to 2010 indicates that this simple method is quit robust and reliable as long as the forest/woodland mask is accurate.
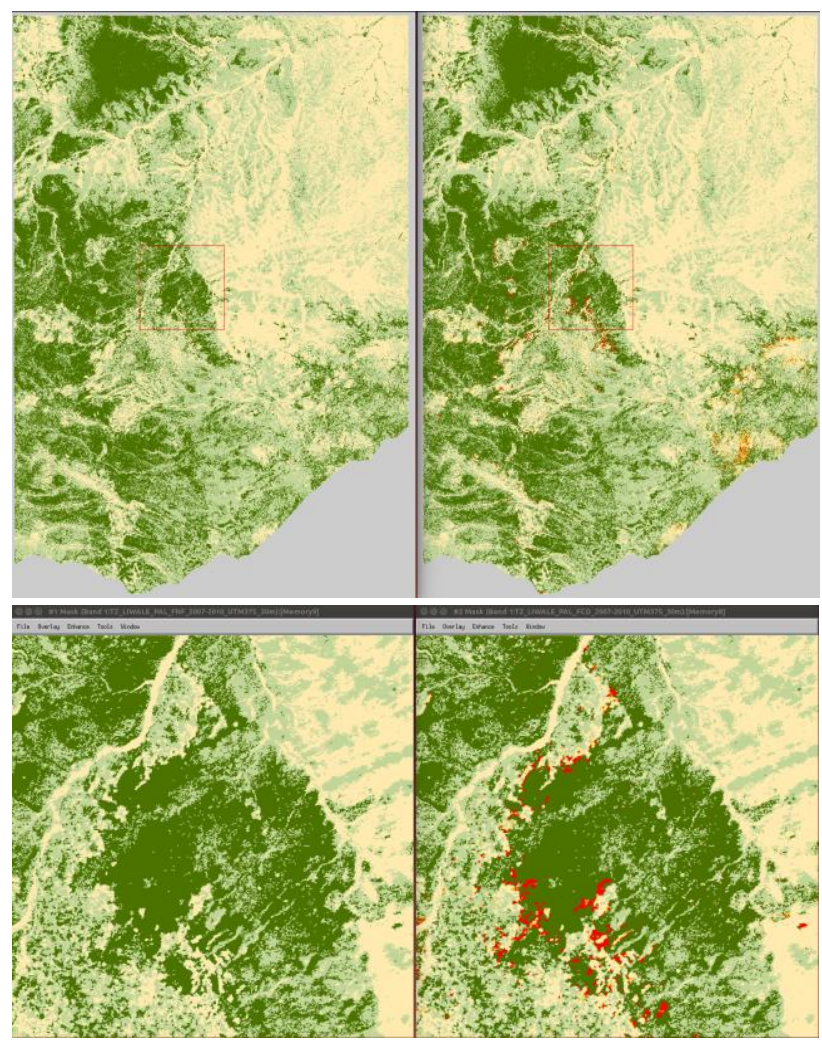

Figure 6. (Left) forest/woodland mask from classifying the maximum HH and HV backscatter mosaics. (Right) 2007-2010

forest and woodland loss in red and orange, respectively. 
Single forest/woodland loss or forest gain pixels have been filtered out as they are often due to speckle effects.

\section{VALIDATION}

The accuracy of the forest-woodland-non forest classification was determined visually using a very high resolution (VHR) satellite image WorldView, with $4 \mathrm{~m}$ resolution, from 12.04.2009. In addition, the forest change mapping was visually checked against VHR optical images from different years (Ikonos, Digital Globe, Rapid Eye and WorldView).

For the accuracy assessment, a set of 250 random points was created across the WorldView image; of these, a total of 134 points were located in cloud and shadow free areas and were classified visually. The visual classification is based on an area of approximately $100 \times 100 \mathrm{~m}$ around each point. Prior to visual classification, the observer was trained by comparing NAFORMA field observations with the WorldView image. The visual classification is divided into three classes: forest, woodland and other (non forest), where woodland includes all woodland with $>10 \%$ tree crown cover.

The result of the visual accuracy assessment (Table 1) shows that the producer's accuracy of the three classes vary between 0.65 and 0.96 . The overall accuracy of the classification is $73.1 \%$. The main confusion is in the classification of woodland, of which $24 \%$ is classified as forest and $12 \%$ as non forest. Two examples (Fig. 7), comparing the classified image with the WorldView image, show that the classification correctly identifies the main landscape patterns.

Table 1. Confusion table for a forest/woodland/non-forest classification. PA: producer's accuracy. UA: user's accuracy.

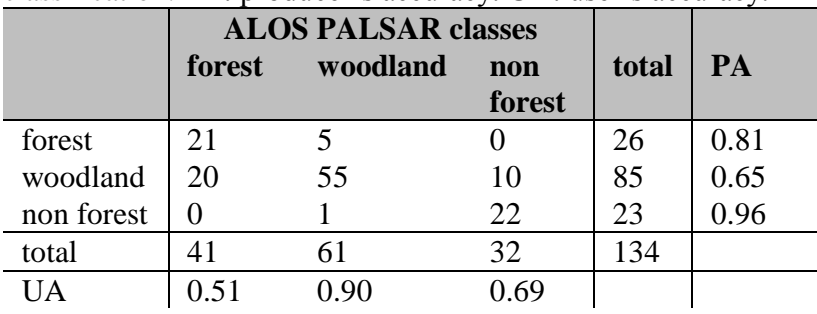

Average accuracy $(P A) 80.4 \%$

Average reliability (UA) $70.0 \%$

Overall accuracy $73.1 \%$

When combining the forest and woodland classes into a forest (= forest + woodland) - non forest classification, the overall accuracy increases to $91.8 \%$ (Table 2). About $9 \%$ of the reference forest pixels were classified as non-forest, indicating that the extent of forest could be underestimated in this classification.

Table 2. Confusion table for a forest/non-forest classification. PA: producer's accuracy. UA: user's accuracy.

\begin{tabular}{|c|c|c|c|c|}
\hline & \multicolumn{2}{|c|}{ ALOS PALSAR classes } & \multirow[b]{2}{*}{ total } & \multirow[b]{2}{*}{ PA } \\
\hline & forest & non forest & & \\
\hline forest & 101 & 10 & 111 & 0.91 \\
\hline non forest & 1 & 22 & 23 & 0.96 \\
\hline total & 102 & 32 & 134 & \\
\hline UA & 0.99 & 0.69 & & \\
\hline
\end{tabular}

Average accuracy (PA) $93.3 \%$

Average reliability (UA) $83.9 \%$

Overall accuracy $91.8 \%$
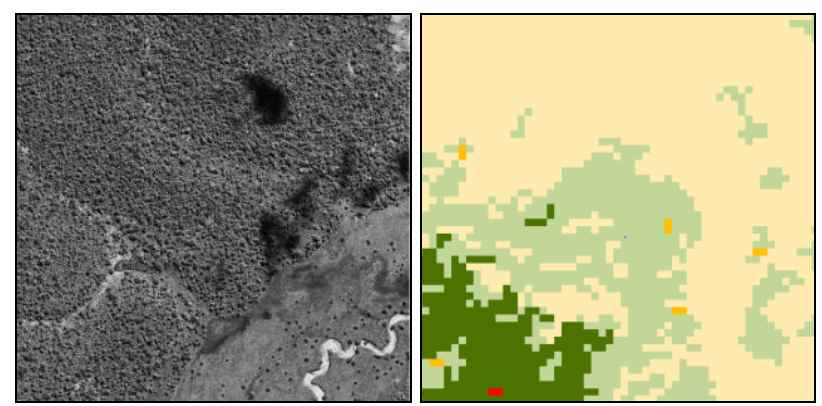

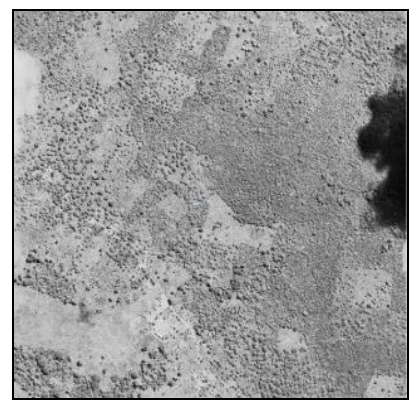

WorldView image

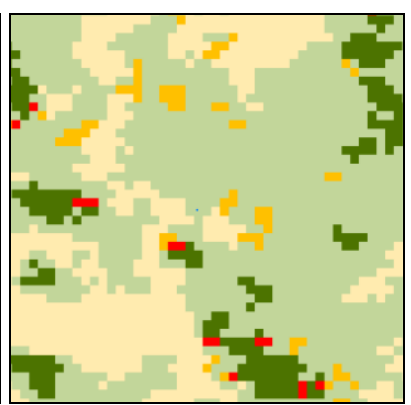

Classified image
Figure 7. Two examples of the classified ALOS PALSAR image compared with the WorldView image. Dark green: forest.

Light green: woodland. Beige: non-forest. Red: forest loss. Orange: woodland loss.
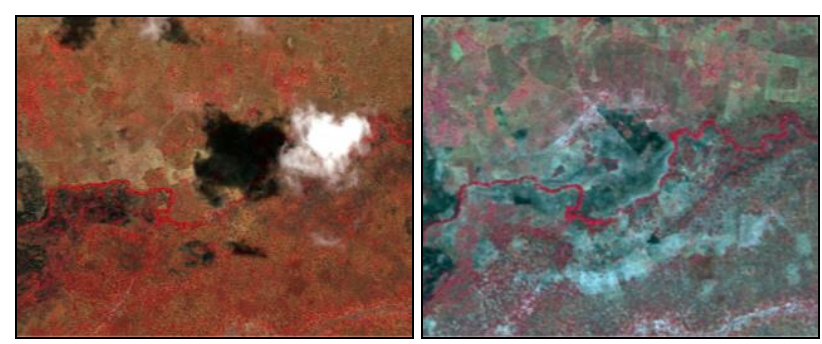

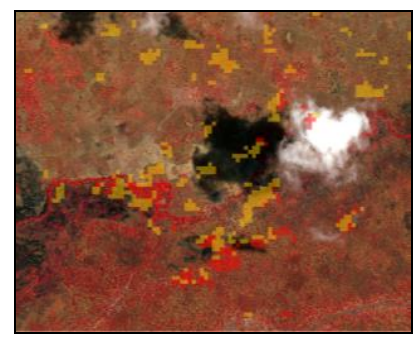

Ikonos 2008

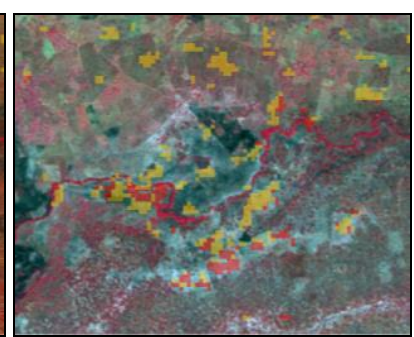

RapidEye 2012S
Figure 8. Example of an area where forest and woodland loss was identified. On the left an Ikonos image from 2008, on the right a RapidEye image from 2012. The forest and woodland loss classes (in red and orange, respectively) are overlain on the bottom two images.

The accuracy of the classified forest change between 2007 and 2010 is difficult to properly validate because of the limited availability of overlapping VHR images of the same years. The mapped deforested areas were visually checked against pairs of overlapping VHR images: Ikonos images from 2008 and 2010, the Ikonos image from 2008 against a RapidEye image from 2012, and a WorldView image from 2009 against a 2012 RapidEye image. The comparison showed that the main trends are correctly classified, although single pixels classified as forest or woodland loss tend to be mostly noise. Fig. 8 shows an 
example of an area where forest and woodland are changed into agricultural land. The images are from 2008 and 2012 and it is therefore not possible to identify the exact timing of deforestation. However, the forest/woodland loss classes appear to match well with areas where deforestation is clearly ongoing. One should keep in mind, however, that deforested areas in the RapidEye image from 2012 may have been deforested after 2010 and are therefore not picked up in the forest/woodland loss classes of 2007-2010.

\section{CONCLUSION}

C- and L-band SAR imagery have been analysed over a study site in Liwale district in Lindi region in Tanzania. At least Lband SAR imagery has been shown to be a suitable instrument to classify into forest, woodland and non-forest with an overall accuracy of about $73 \%$. Aggregating the forest and woodland class into one forest class results in accuracies of about $92 \%$. The classification method presented and used here is a combination of a Gaussian Mixture Model and a k-means classifier. C-band SAR alone seems to underestimate the woodland areas compared to the L-band classification, but combing $\mathrm{C}$-and L-band inside the classifier increases the woodland area even compared to the single sensor L-band classification. C-band and multi-sensor classification results have not been validated at this stage. A forest/woodland/nonforest classification based on the maximum backscatter from the time period 2007 to 2010 has been used as a forest/woodland mask to detect forest changes from inter-annual HV backscatter variation higher than $3 \mathrm{~dB}$. Comparison of added single year forest loss with a 3 year loss and a visual assessment with VHR optical satellite data shows that the forest loss detection method seems to be robust. C-band SAR data has not yet been analysed for forest change detection, but is planned for future studies.

\section{ACKNOWLEDGEMENTS}

Funding for this study has been provided by the Norwegian Embassy in Dar-Es-Salam in Tanzania through a contract with Sokoine University of Agriculture. Additional funding at Norut was provided by the Norwegian Research Council through grant nr. 204430/E40. Ground reference land cover type data has been provided by the NAFORMA project, funded by FAO and Finland. Envisat ASAR and ALOS Palsar satellite data has been provided by ESA and JAXA, respectively, though GEO FCT. Additional data sets were provided by ESA through a Category1 project nr. 27689. VHR optical data has been provided by DigitalGlobe, Ikonos and RapidEye through the KSAT/GEOFCT/GFOI.

\section{REFERENCES}

GFOI, 2013. Review of Priority Research \& Development Topics: R\&D related to the use of Remote Sensing in National Forest Monitoring. Pub. GEO, Switzerland, 2013 ISBN 978-92990047-5-3.

Haarpaintner, J., Ø. Due Trier, and J. Otieno, 2012. GEO FCT Product Development Team report - Tanzania. Oral presentation at the GEO-FCT Science \& Data Summit \#3, Arusha, Tanzania, 6-10 Feb. 2012.
Larsen, Y., G. Engen, T.R. Lauknes, E. Malnes, and K.A. Høgda, 2005. A generic differential interferometric SAR processing system, with applications to land subsidence and snow-water equivalent retrieval. Proc. FRINGE 2005, Frascati, Italy, Nov 28 - Dec 2, 2005.

Shimada, M., and O. Takahiro, 2010. Generating Large-Scale High-Quality SAR Mosaic Datasets: Application to PALSAR Data for Global Monitoring. IEEE journal of selected topics in applied earth observations and remote sensing, 3(4), pp. 637656.

Tomppo, E., R. Malimbwi, M. Katila, K. Mäkisara, H.M. Henttonen, N. Chamuya, E. Zahabu, and J. Otieno, 2014. A sampling design for a large area forest inventory: case Tanzania. Canadian Journal of Forest Research, 44(8), pp. 931-948.

Ulander, L., 1996. Radiometric slope correction of synthetic aperture radar images. IEEE Transactions on Geoscience and Remote Sensing,34(5), pp.1115-1122. 